Gompels, A. E. H. (1935). J. gen. Microbiol. 9, 140-148.

\title{
Antigenic Relationships of Swine Influenza Virus
}

\author{
BY ANNETTE E. H. GOMPELS \\ National Institute for Medical Research, Mill Hill, London, N.W.7
}

SUMMARY: Antigenic comparisons of six strains of swine influenza virus with three strains of human influenza $A$ virus were made by the agglutination-inhibition technique. The strains were also compared in regard to inhibition by normal sera, rate of elution from red cells, pathogenicity for mice, and other properties. All swine strains were significantly different from human strains. Four American swine strains formed a fairly homogeneous group, but were less closely related to two strains recovered in the United Kingdom. The findings are briefly discussed in terms of the relationship between human and swine influenza.

Human influenza A viruses recovered from succeeding epidemics exhibit varying degrees of difference in antigenic structure. In order to ascertain whether this occurred among strains of swine influenza virus, the antigenic structure of standard strains of swine influenza virus was compared with that of some more recently isolated strains.

The earliest work on this subject was carried out by Shope (1935-6, 1936, $1937 a, b, 1938)$ in his extensive researches on swine influenza. Following studies on immunological and serological relationships between swine and human viruses, Shope concluded in agreement with Laidlaw (1935) that swine influenza might well have had its origin from the 1918-19 human influenza pandemic virus.

Isolation of strains of swine influenza in the British Isles (Lamont, 1938; Blakemore \& Gledhill, 1941) was followed by a survey of the antigenic relationship of British swine influenza strains to standard human and swine influenza viruses by means of the agglutination-inhibition tests with chicken and ferret antisera by Hudson, Sigel \& Markham (1943) and by Glover \& Andrewes (1943). Since then, however, methods have been evolved for the destruction of non-specific inhibitor in normal sera, and serological relationships, as indicated by haemagglutination-inhibition tests, can now be more clearly demonstrated. It is interesting to review the relationship between human and swine influenza viruses in the light of recent techniques.

\section{MATERIALS}

Virus strains. The standard laboratory strains of swine influenza, Shope 15 (1931) and Cambridge (Blakemore \& Gledhill, 1941) and the standard strains of human influenza A were obtained from the World Influenza Centre (W.I.C.). One Northern Ireland Standard strain (Lamont, 1938) and two American strains of swine influenza, Felin 1949 and Vogt 1946, were obtained through the courtesy of Dr R. E. Shope. A third American strain of swine influenza virus, Wisconsin 1949, was obtained through Prof. W. I. B. Beveridge from Dr Kissling.

All strains were passed allantoically in 10-day-old chick embryos. After 
$48 \mathrm{hr}$. incubation at $35^{\circ}$ the allantoic fluids were chilled, harvested, lightly centrifuged and the supernatants titrated and stored in capillary tubes and ampoules at $-70^{\circ}$. Subsequent egg passes for allantoic fluid material were made from this stock.

Sera. Normal ferret serum and standard antisera from the W.I.C. were used for serological tests.

Ferret antisera were prepared against Wisconsin, Felin, Cambridge and Northern Ireland strains by bleeding ferrets 12 days after intranasal instillation of $1 \mathrm{ml}$. of freshly harvested allantoic fluid diluted $10^{-2}$ in broth saline.

For haemagglutination-inhibition tests all sera were treated with R.D.E. eluate (Van der Veen \& Mulder, 1950; Isaacs \& Bozzo, 1951).

Receptor-destroying enzyme (R.D.E.). An extract of the $4 \mathrm{Z}$ strain of Vibrio cholerae containing the R.D.E. was prepared by the method of Burnet \& Stone (1947), and from this an eluate was prepared by absorption and elution on fowl red cells. The preparation of R.D.E. used in these experiments had a titre of 1600 units/ml. as tested with MEL virus (Burnet \& Stone, 1947).

Red cells. A standardized $\frac{1}{2} \%$ chick erythrocyte suspension was used for all titrations except where specified.

R.D.E.-treated red cells. Dilutions of R.D.E. were prepared in calcium-acetate buffer, pH 6.0. To $4 \mathrm{ml}$. volumes of each dilution, $0.1 \mathrm{ml}$. of packed fowl red cells was added and incubated for $\frac{1}{2} \mathrm{hr}$. at $37^{\circ}$. Sodium citrate was then added to give a final concentration of $2 \%$ and the cells were centrifuged, washed in $2 \%$ citrate saline and finally suspended in $2 \%$ citrate saline to make a $1 \%$ red cell suspension.

\section{METHODS}

Complement-fixation tests were carried out using a modification of Hoyle's (1948) technique. Soluble antigen was prepared from infected chorio-allantoic membranes and titrated against convalescent $A$ and $B$ human influenza antisera.

Haemagglutination-inhibition tests. Serial twofold dilutions $(0.25 \mathrm{ml}$.$) of$ serum were prepared in normal saline and an equal volume of $\frac{1}{2} \%$ fowl red cells was added to each dilution, followed by eight agglutinating doses (8 A.D.) of virus in $0.25 \mathrm{ml}$. The cells were allowed to settle at room temperature, and readings were made by the pattern method. Partial, one plus $(+)$ agglutination-inhibition was taken as the end-point. 1 A.D. of virus is defined as the least amount of virus which will produce partial or one plus agglutination.

Treatment of sera. To reduce the non-specific inhibitor present in normal sera, ferret sera were incubated overnight at $37^{\circ}$ with a suitable dilution of R.D.E. and then inactivated by heating at $56^{\circ}$ for $1 \mathrm{hr}$.

Test of destruction of non-specific serum inhibitor. In a preliminary test, the amount of non-specific inhibitor present in R.D.E. treated and untreated sera was estimated by titration of the so-called Francis inhibitor, i.e. measuring the inhibitory titre of serum for heated influenza $B$ virus.

Serial twofold dilutions $(0.25 \mathrm{ml}$.) of antiserum in normal saline were prepared, and an equal volume of 5 A.D. of influenza $B$ virus previously heated for $\frac{1}{2} \mathrm{hr}$. at $56^{\circ}$, was added to each dilution. This was left to stand at room 
temperature for $\frac{1}{2} \mathrm{hr}$. before adding a final volume of $0.25 \mathrm{ml}$. of $\frac{1}{2} \%$ inhibitorsensitive fowl cells (Anderson, Burnet \& Stone, 1946). The cells were left to settle at room temperature, and readings were made in the same way as in the anti-haemagglutinin titration. Reduction to $1 \%$ of the amount of non-specific inhibitor present in the untreated ferret serum was considered sufficient, since the amount remaining would not interfere with the readings of the haemagglutination-inhibition titrations.

Absorption and elution from red cells. Experiments on the comparative rates of elution of swine influenza virus strains from fowl red cells were carried out on $1 \%$ suspensions of cells in virus diluted to a concentration of 320 A.D. per $0.25 \mathrm{ml}$. Absorption was carried out at $2^{\circ}$ for $\frac{1}{2} \mathrm{hr}$, and elution at $37^{\circ}$ over a period of $24 \mathrm{hr}$.

Fowl red cell receptor gradient. The relative positions of the swine influenza strains on the receptor gradient were assessed with R.D.E.-treated chick cells using the method adopted by Burnet, McCrea \& Stone (1946).

Mouse and egg infectivity tests were carried out using the same inocula for albino mice, and 10-day egg embryos. Each mouse received $0.05 \mathrm{ml}$. of inoculum intranasally under light anaesthesia, and deaths were recorded over a period of 14 days. Thereafter, the lung lesions of the survivors were examined. Each egg was inoculated allantoically with $0.05 \mathrm{ml}$. of inoculum and harvested after 3 days' incubation at $35^{\circ}$. The dilutions at which $50 \%$ of the eggs were infected, E.I.D. 50, and at which the mice showed $50 \%$ lung lesions, were determined according to the method described by Reed \& Muench (1938).

Cross-neutralization tests were carried out on 10-day chick embryos. Equal volumes of suitably diluted virus and dilutions of inactivated serum were mixed and allowed to stand for $15 \mathrm{~min}$. at $2^{\circ}$. Eggs were inoculated allantoically with $0.05 \mathrm{ml}$. serum virus mixture and incubated at $35^{\circ}$ for 3 days.

\section{RESULTS}

Complement-fixation tests on the strains of swine and human influenza demonstrated the existence of a common soluble antigen for human $\mathbf{A}$ influenza and swine influenza, but no relationship between human $B$ influenza and swine influenza viruses (see Table 1). No quantitative differences were observed between the titres with human serum titrated against human or swine influenza.

Haemagglutination-inhibition tests were carried out to determine the extent to which swine influenza strains would be inhibited by normal ferret serum. Of the six strains of swine influenza, the Cambridge and Northern Ireland strains were significantly inhibited by normal ferret serum (see Table 2). No strains of human influenza $A$ or $B$ viruses are known which are not inhibited to a significant titre by normal ferret serum.

Subsequent experiments on the nature of this non-specific inhibitor proved it to be stable after heating for $30 \mathrm{~min}$. at $65^{\circ}$ but sensitive to treatment with R.D.E. eluate. Similar properties have been noted by Isaacs \& Bozzo (1951) for the non-specific inhibitor of human influenza strains in normal ferret serum. The inhibitor has therefore similar properties to the 'Francis' inhibitor. 
Table 1. Complement-fixation test

Titration of influenza soluble antigens against human influenza $A$ and $B$ convalescent sera Antigen titre with

Soluble antigen

Swine:

Shope

Cambridge

Vogt

Felin

Wisconsin

Northern Ireland

Human:

$\mathbf{A}$

$\overbrace{1 / 16 \mathrm{~A} \text { serum } \quad 1 / 16 \mathrm{~B} \text { serum Buffer control }}^{\text {1/2 }}$

$\begin{array}{rrr}\mathbf{8} & <2 & <2 \\ 16 & <2 & <2 \\ 8 & <2 & <2 \\ 7 & <2 & <2 \\ 20 & <2 & <2 \\ 32 & <2 & <2 \\ & & <2 \\ 96 & <2 & <2\end{array}$

Table 2. Inhibition of swine and standard human strains of influenza by pooled normal ferret serum

\section{Virus strains}

Swine:

Shope 15

Cambridge

Vogt

Felin

Wisconsin

Northern Ireland

Human :

PR 8

WS-38

FM 1
Haemagglutinationinhibition titre

Table 3. Titres of ferret sera against human and swine influenza viruses

\begin{tabular}{|c|c|c|c|c|c|c|c|c|c|}
\hline \multirow[b]{2}{*}{ Virus } & \multirow[b]{2}{*}{$\begin{array}{l}\text { Year of } \\
\text { isolation }\end{array}$} & \multicolumn{8}{|c|}{ Serum } \\
\hline & & Shope & $\begin{array}{l}\text { Northern } \\
\text { Ireland }\end{array}$ & Cambridge & Wisconsin & Felin & WS & PR 8 & FM1 \\
\hline Shope & 1931 & 960 & $<10$ & 160 & 20 & 80 & $<10$ & $<10$ & $<10$ \\
\hline Northern Ireland & 1938 & $<10$ & 2560 & $<10$ & - & - & $\mathbf{3 2 0}$ & $<10$ & $<10$ \\
\hline Cambridge & 1941 & $\mathbf{3 8 4 0}$ & 60 & 5120 & 20 & 20 & 200 & $<10$ & 100 \\
\hline Wisconsin & 1949 & 100 & $<10$ & $<10$ & 240 & 320 & $<10$ & $<10$ & $<10$ \\
\hline Vogt & 1946 & 160 & $<10$ & $<10$ & 80 & 800 & $<10$ & $<10$ & $<10$ \\
\hline Felin & 1949 & 160 & $<10$ & $<10$ & 160 & 1280 & $<10$ & $<10$ & $<10$ \\
\hline WS & 1938 & $<10$ & $<10$ & $<10$ & $<10$ & 40 & $\mathbf{5 1 2 0}$ & 40 & $<10$ \\
\hline PR 8 & 1934 & $<10$ & $<10$ & $<10$ & $<10$ & 20 & 160 & 5120 & $<10$ \\
\hline FM1 & 1947 & $<10$ & $<10$ & $<10$ & $<10$ & $<10$ & $<10$ & $<10$ & 1280 \\
\hline
\end{tabular}

The results of the haemagglutination-inhibition tests using R.D.E.-treated ferret sera prepared against swine and influenza viruses (Table 3) showed close, though not identical, antigenic relationships among the American swine influenza strains. However, no such relationships were found between the swine influenza strains and any of the main subtypes of the human influenza $A$ strains.

It is interesting to note that the Shope strain (1931) shows a fairly close antigenic relationship with the more recently isolated strains of Vogt, Wisconsin 
and Felin which is in contrast to the divergence of antigenic structure exhibited in comparable tests with earlier (WS and PR8) and more recently isolated (FM1, 1947) strains of human influenza $A$ virus.

The Northern Ireland strain showed no antigenic relationship to the American swine strains, and was apparently only distantly related to the Cambridge swine strain. Both the Northern Ireland and the Cambridge strains were inhibited by WS antiserum, and the latter also by FM1 antiserum. The Cambridge strain, however, exhibited a significant antigenic relationship with the Shope strain, although not with Vogt, Felin and Wisconsin, American strains related to Shope 15.

WS and PR 8 viruses were inhibited to low titre by Felin serum. This was the only swine antiserum which showed inhibition of the human influenza virus strains.

Cross-neutralization tests. In an attempt to confirm the relationships between Cambridge swine and human influenza $A$ viruses found in the haemagglutination-inhibition tests, cross-neutralization tests were carried out in eggs.

Table 4 shows comparative titres of a number of sera tested in haemagglutination-inhibition tests and egg neutralization tests. Although no direct correspondence was found between the titres in the different tests, there is a general similarity in the results of the two tests, except for the results with Felin serum.

\section{Table 4. Relationship between egg neutralization and haemagglutination- inhibition tests with Cambridge virus}

$\begin{array}{lcc}\begin{array}{c}50 \% \text { virus } \\ \text { Antiserum }\end{array} & \begin{array}{c}50 \% \text { haemagglutina- } \\ \text { neutralization } \\ \text { titre in eggs }\end{array} & \begin{array}{c}\text { tion-inhibition titre } \\ \text { against } 8 \text { A.D. virus }\end{array} \\ \begin{array}{l}\text { Swine: } \\ \text { Shope 15 }\end{array} & 70 & \mathbf{3 8 4 0} \\ \text { Cambridge } & >320 & 5120 \\ \text { Felin } & 40 & 20 \\ \text { Human: } & & \\ \text { FM 1 } & 4 & 100 \\ \text { WS } & 6 & 200 \\ \text { PR8 } & <4 & <10 \\ \text { Normal ferret } & <4 & <10\end{array}$

Rates of elution of virus from red cells. Comparative studies made on the rates of elution of 320 A.D. per $0.25 \mathrm{ml}$. of each strain of swine influenza virus from a $1 \%$ suspension of chicken erythrocytes showed complete elution of the Cambridge strain within an hour, while Shope 15 strain failed to elute completely even after 24 hr. incubation. The remaining strains range between these two extremes-see Fig. 1.

Red cell receptor gradient. These results prompted an investigation into the comparative positions of individual swine influenza strains on the red cell receptor gradient. Table 5 shows the titre of R.D.E. which removed red cell receptors to a standard degree, i.e. to produce $50 \%$ agglutination by 5 A.D. of the test virus. 
Experiments with R.D.E.-treated erythrocytes showed a fairly uniform behaviour of the swine strains with the exception of Cambridge virus which was a little 'earlier' in the gradient.

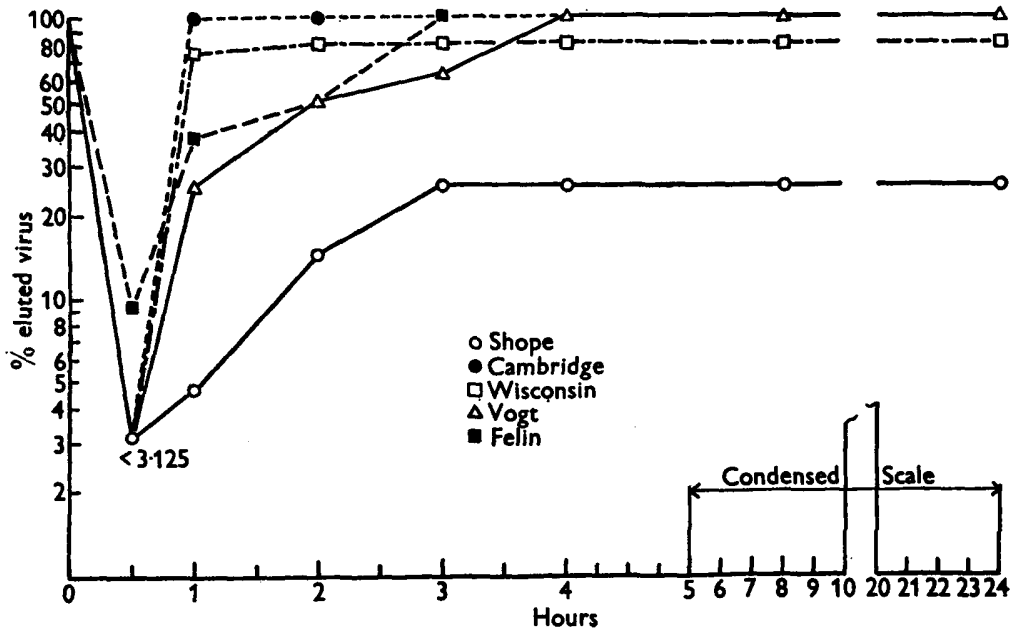

Fig. 1. Comparative rates of elution of swine influenza virus strains from fowl red cells.

Table 5. Agglutination of R.D.E.-treated forel red cells by 5 A.D. of swine influenza virus strains

Dilution of R.D.E. at which $50 \%$ agglutination

Virus strain occurred

Shope 15 80

Vogt

80

Felin 120

Wisconsin

80

Cambridge 240

Northern Ireland

80

Table 6. Comparison of egg infectivity and mouse pathogenicity of the swine influenza strains

Titres show infectivity per $0.05 \mathrm{ml}$. allantoic fluid

\begin{tabular}{lccc}
\multicolumn{1}{c}{$\begin{array}{c}\text { A. Egg infectivity, } \\
\text { E.1.D. 50 }\end{array}$} & $\begin{array}{c}\text { B. Mouse patho- } \\
\text { genicity, 50\% } \\
\text { lesion dose }\end{array}$ & $\begin{array}{c}\text { Ratio A:B } \\
\text { (in logs) }\end{array}$ \\
Cambridge & & $10^{-5 \cdot 5}$ & 2 \\
Northern Ireland & $10^{-7 \cdot 5}$ & $10^{-6.7}$ & $0 \cdot 8$ \\
Shope 15 & $10^{-7 \cdot 5}$ & $10^{-7 \cdot 5}$ & $0 \cdot 2$ \\
Vogt & $10^{-7 \cdot 7}$ & $10^{-2 \cdot 5}$ & $\mathbf{3 \cdot 5}$ \\
Felin & $10^{-6}$ & $10^{-2.5}$ & 4 \\
Wisconsin & $10^{-6.5}$ & $10^{-2}$ & 5
\end{tabular}

Egg and mouse infectivity tests. It has been shown that the previous passage history of a virus can play an important part in altering its pathogenicity and infectivity titres in any particular host.

Table 6 is a comparison of concurrent egg and mouse infectivity tests 
carried out on the stock material used in these experiments. These tests showed that the swine influenza viruses varied considerably in their mouse pathogenicity. While the adapted Standard Laboratory strains, e.g. Shope 15, Cambridge and Northern Ireland showed high titres in mice, the more recently isolated, unadapted strains, e.g. Vogt and Felin, showed in contrast comparatively low mouse infectivity titres.

\section{DISCUSSION}

The relationships between human $\mathbf{A}$ and swine influenza have been an intriguing problem for some time. Apart from the fact that the two clinical diseases are not dissimilar, the causative viruses show a number of striking similarities.

(1) Both viruses will grow in swine, ferrets and mice after intranasal instillation.

(2) Both viruses will grow in the amniotic and allantoic cavities of chick embryos.

(3) Both viruses agglutinate fowl and mammalian blood cells.

(4) The viruses share a common soluble antigen.

There are three possibilities which might explain these relationships.

The first possibility is that the viruses of swine and human influenza are closely related, with swine influenza acting as a reservoir for human influenza. In support of this is the occurrence of influenza $A$ in pigs after experimental infection with human influenza A viruses (Shope \& Francis, 1936) and as a result of swine becoming naturally infected with human influenza virus (Shope, 1938). However, no instances have been recorded of the reverse procedure, i.e. man becoming infected with swine influenza either experimentally or as a result of coming in contact with swine suffering from the disease. Again, cross-haemagglutination-inhibition tests with immune ferret sera demonstrate that there is no close antigenic relationship between recently isolated swine and recently isolated human influenza viruses.

This leads to the consideration of a second possibility suggested by Laidlaw (1935) and subscribed to by Shope (1935-6) that the swine influenza virus might represent a surviving prototype of the human virus of the 1919 pandemic. In that case it would appear that the human, but not the swine viruses, have diverged widely in antigenic relationship from the originally isolated strains. The swine strains of Shope 15 and Felin isolated 18 years apart, show remarkable similarities in their antigenic relationships, lack of inhibition by normal ferret serum, and position in the red cell receptor gradient. It is interesting to note, however, that there are some biological differences, e.g. pathogenicity in mice, between Shope 15 and more recently isolated swine strains. On the other hand, striking serological differences have been found in human A strains isolated between 1933 and 1947 (Van der Veen $\&$ Mulder, 1950). These facts, taken along with the evidence from studies of human sera, are against any hypothesis that human influenza $A$ viruses are at present evolving from swine influenza viruses. 
A third possibility is that human and swine influenza viruses may have arisen from a common prototype in the past, and that human and swine strains, while retaining a few common characteristics, have since evolved along rather different antigenic lines.

It is possible that swine influenza may have become endemic in the United States, and that the original Shope 15 strain isolated in 1931 has largely maintained its biological characters since then. This is shown by its close serological relationships with the more recently isolated strains of Vogt 1946 and Felin 1949. It is, however, doubtful whether swine influenza is still prevalent in Europe. There have been no reports of it since 1941 (Blakemore \& Gledhill), and although there is evidence of a widespread chronic virus pneumonia of pigs (Beveridge \& Gulrajani, 1951; Betts, 1952), the aetiological agent is apparently quite unrelated to that of swine influenza.

Much gratitude is due to Dr C. H. Andrewes, F.R.S., and Dr A. Isaacs for constant help and advice.

This work was carried out while the author was in receipt of a personal grant from the South African Institute for Medical Research, Johannesburg.

\section{REFERENCES}

Anderson, S. G., Burnet, F. M. \& Stone, J. D. (1946). Modified Salk test for in vitro titration of influenza antibodies. Aust. J. exp. Biol. med. Sci. 24, 269.

Betrs, A. O. (1952). Respiratory diseases of pigs. V. Some clinical and epidemiological aspects of virus pneumonia of pigs. Vet. Rec. 64, 283.

Beveridge, W. I. B. \& Gulrajan, I. S. (1951). Studies on respiratory diseases of pigs. IV. Transmission of infectious pneumonia and its differentiation from swine influenza. J. comp. Path. 61, 118.

Blakemore, F. \& GledHill, A. W. (1941). Swine influenza in the British Isles. Proc. R. Soc. Med. 34, 611 .

Burnet, F. M., McCrea, J. F. \& Stone, J. D. (1946). Modification of human red cells by virus action. I. The receptor gradient for virus action in human red cells. Brit. J. exp. Path. 27, 228.

Burnet, F. M. \& Stone, J. D. (1947). The receptor destroying enzyme of $V$. cholerae. Aust. J. exp. Biol. med. Sci. 25, 227.

GLover, R. E. \& ANDrewes, C. H. (1943). The antigenic structure of British strains of swine influenza virus. J. comp. Path. Therap. 53, 329.

HoyLe, L. (1948). Technique of the complement-fixation test in influenza. Mon. Bull. Min. Hlth, p. 114.

Hudson, N. P., Sigel, M. M. \& MarkhaM, F. S. (1943). Antigenic relationship of British swine influenza strains to standard human and swine influenza viruses. J. exp. Med. 77, 467 .

IsaAcs, A. \& Bozzo, A. (1951). The use of $V$. cholerae filtrates in the destruction of non-specific inhibitor in ferret serum. Brit. J. exp. Path. 32, 325.

LaIDLAw, P. P. (1935). Epidemic influenza: a virus disease. Lancet, $i, 1118$.

LAMONT, H. G. (1938). The problems of the practitioner in connection with the differential diagnosis and treatment of diseases of young pigs. Vet. Rec. 50, 1377.

REed, L. J. \& Muench, H. (1938). A simple method of estimating fifty per cent endpoints. Amer. J. Hyg. 27, 493.

Shope, R. E. (1935-6). The influenzas of swine and man. Harvey Lect. p. 183.

SHOPE, R. E. (1936). Immunization experiments with swine influenza virus. J. exp. Med. 64, 47. 
Shope, R. E. \& Francis, T. F., Jr. (1936). The susceptibility of swine to the virus of human influenza. J. exp. Med. 64, 791.

SHope, R. E. (1937a). Recent knowledge concerning influenza. Ann. intern. Med. $11,1$.

SHOPE, R. E. (1937b). Immunological relationship between the swine and human influenza viruses in swine. J. exp. Med. 66, 151.

Shope, R. E. (1938). Serological evidence for the occurrence of infection with human influenza virus in swine. J. exp. Med. 67, 739.

Van der Veen, J. \& Mulder, J. (1950). Studies of the Antigenic Composition of human Influenza Virus A Strains. Leiden: Stenfert Kroese.

(Received 20 March 1953) 